\title{
Impact of nutrient warning labels on choice of ultra- processed food and drinks high in sugar, sodium, and saturated fat in Colombia: A randomized controlled trial
}

\author{
Mercedes Mora-Plazas \\ Universidad Nacional de Colombia \\ Isabella Higgins \\ University of North Carolina at Chapel Hill \\ Luis Fernando Gomez \\ Pontificia Universidad de Javeriana \\ Marissa G. Hall \\ University of North Carolina at Chapel Hill \\ Maria Fernanda Parra \\ Pontificia Universidad Javeriana \\ Maxime Bercholz \\ University of North Carolina at Chapel Hill \\ Nandita Murukutla \\ Vital Strategies \\ Lindsey Smith Taillie ( $\nabla$ taillie@unc.edu ) \\ University of North Carolina at Chapel Hill
}

\section{Research Article}

Keywords: front-of-package labeling, sugar-sweetened beverages, added sugar, obesity prevention, food policy, Latin America

Posted Date: February 17th, 2021

DOI: https://doi.org/10.21203/rs.3.rs-252879/v1

License: (c) (i) This work is licensed under a Creative Commons Attribution 4.0 International License. Read Full License 


\section{Abstract}

\section{Background}

Front-of-package nutrient warning labels are one promising policy to inform healthier food choices and purchasing decisions. This study aimed to identify the impact of nutrient warning labels on product selection and the ability to correctly identify products with an excess of critical nutrients, among other outcomes in Colombia.

\section{Methods}

We conducted an online randomized experiment among 8,061 Colombian adults in October 2020. Participants were randomly assigned to a front-of-package label condition: nutrient warning, guideline daily amounts (GDA), Nutri-Score, or a no-label condition. First, they viewed a fruit drink with added sugar that was labeled per their assigned condition and one without added sugar, which was only labeled in the GDA and Nutri-Score conditions, and completed selection tasks. The primary outcomes were 1) selection of the fruit drink with added sugar as the fruit drink they would rather buy and 2) correctly identifying which fruit drink was higher in sugar. Next, they viewed four food products (cookies, yogurt, sliced bread, and breakfast cereal) with their assigned condition and answered a series of questions. Finally, they selected which of the three label types would most discourage them from consuming a specified ultraprocessed food.

\section{Results}

Fewer participants in the nutrient warning condition (20\%) selected the added sugar fruit drink as the product they would rather buy compared to $24 \%$ in the GDA condition ( $p<.01), 29 \%$ in the no-label condition, and $33 \%$ in the Nutri-Score condition (both, $p<.001$ ). More participants in the nutrient warning condition (88\%) correctly identified the fruit drink higher in sugar compared to the no-label condition $(68 \%)$ and the Nutri-Score condition (65\%) (both, $p<.001$ ). More participants in the GDA condition (91\%) correctly identified the fruit drink higher in sugar compared to the nutrient warning condition $(p<.01)$. Most participants (72\%) selected the nutrient warning label as most discouraging, while only $20 \%$ selected the GDA label and $9 \%$ selected the Nutri-Score label.

\section{Conclusions}

Nutrient warning labels are a promising policy strategy to prevent obesity and diet-related noncommunicable diseases in Colombia. Future research is needed to understand the impact of nutrient warning labels on actual ultra-processed food purchases in Colombia.

Trial Registration: NCT04567004

\section{Background}


The global obesity pandemic and diet-related non-communicable diseases (NCD) have become great health challenges, posing risks to the health and lives of individuals, the well-being of families, economic development [1, 2], and the sustainability of the food system [3]. Ultra-processed foods and beverages are generally low in beneficial nutrients like fiber, protein, micronutrients, and bioactive compounds [4-6], and they are mostly high in nutrients related to chronic diseases such as sugar, sodium, and saturated fat [7]. There is compelling evidence about the link between the shift from consumption of unprocessed foods to ultra-processed foods and the increase in obesity and diet-related NCD [8-11].

Colombia is not immune to such health challenges. According to the Colombian National Nutritional Health Surveys (ENSIN) conducted in 2010 and 2015, the rate of overweight and obesity increased in all age groups. The rate increased from $18.8 \%$ to $24.4 \%$ in school-aged children (5-12 years old), $15.5 \%$ to $17.9 \%$ in adolescents (13-17 years old), and $51.2 \%$ to $56.4 \%$ in adults (18-64 years old) $[12,13]$.

To address the rising prevalence in overweight, obesity and diet-related NCD, scholars, advocates and policymakers are increasingly calling for policies to communicate the health risks of consuming ultraprocessed foods and to discourage their consumption [14, 15]. Front-of-package labels have emerged as one promising policy to guide and influence consumers to make healthier food choices and purchasing decisions [16]. Many countries in the world have applied different front-of-package designs such as guideline daily amounts (GDA) labels, Nutri-Score labels, and nutrient warning labels [17]. Currently, in Latin America, front-of-package nutrient warning labels are required in Peru, Uruguay, Chile, and Mexico. Colombia is considering implementing them as well. In 2016, the Colombian Ministry of Health proposed a regulation to require front-of-package nutrient warning labels [18]. In addition, the Senate is scheduled to debate a bill which would require implementation of a nutrient warning label in Colombia [19].

There is emerging evidence that of the different front-of-package labels, nutrient warning labels, similar to the ones implemented in other Latin American countries, may be most effective at helping consumers to identify unhealthy foods and discourage them from selecting those food products [15]. A recent online randomized controlled trial in Colombia that assessed perceptions of and reactions to different nutrient warning label designs, concluded that the octagonal nutrient warning label performed best, and participants overwhelmingly selected it as the nutrient warning label that most discouraged them from wanting to consume an ultra-processed food product [20]. However, despite evidence supporting the octagonal nutrient warning label as the most effective nutrient warning label, there has not been an evaluation in Colombia of the effectiveness of a nutrient warning label compared to other types of frontof-package nutrient systems. Therefore, the objective of this study was to identify the impact of the nutrient warning label on product selection and ability to correctly identify products higher in sugar, in addition to other outcomes, compared to GDA labels, Nutri-Score labels, and a no-label condition in Colombia.

\section{Methods}


The study was approved by the institutional review board at the University of North Carolina at Chapel Hill and designated as exempt from review at Universidad Nacional de Colombia. Prior to participating in the study, participants acknowleged their informed consent. We pre-registered the design, hypotheses, and analytic plan on ClinicalTrials.gov (\#NCT04567004).

\section{Study design and procedures}

The final labels tested are shown in Figure 1. As the study's purpose was to inform Colombia's front-ofpackage labeling policy, we set out to test front-of-package labels that could be proposed as a result of the policy. Provided this, we decided to test a nutrient warning label, a guideline daily amounts (GDA) label, and a Nutri-Score label as well as a no-label alternative.

We selected the nutrient warning label based on the nutrient warning that performed best in our previous study investigating front-of-package nutrient warning labels. In our previous study, the octagonal nutrient warning elicited the highest perceived message effectiveness (PME) and was the label that most participants selected as discouraging them from purchasing ultra-processed foods and sugary drinks high in nutrients of concern) [20]. The octagonal nutrient warning label was a black octagon that contained a statement about the product containing excess of a nutrient of concern (sugar, sodium, or saturated fat). For example, "EXCESO DE AZÚCAR" (Excess sugar). The octagon also contained "MINSALUD" indicating the message was authorized by the Colombian Ministry of Health and the text “EVITAR SU ALTO CONSUMO” (Avoid high consumption). To determine if a product would receive a nutrient warning label, we used the Chilean Ministry of Health's third stage cutoff limits for sugar, sodium, and saturated fat [21].

The GDA label included Spanish text above the GDA figure stating the product serving size. Below the serving size, a row of light blue blocks listed the Calories, total fat, saturated fat, sugar, and sodium per serving, as well as percentages indicating what percent of the GDA the serving contained. Underneath the light blue blocks, Spanish text explained the percentages were based on the guideline daily amounts for a 2,000-Calorie diet [22].

The Nutri-Score label system, which is currently used voluntarily in some European countries [23], is a color coded and letter rated (A-E) system. A dark green " $\mathrm{A}$ " indicates the best nutritional value and a dark red " $E$ " indicates the worst nutritional value. A product's letter rating is determined based on a point system. A higher point value indicates a less healthy product. The more calories, sugar, sodium, and saturated fat a product contains, the more points it receives. However, a product can also receive negative points for containing fiber, protein, and fruits and vegetables, which can decrease the product's total points [24].

Finally, we decided to also test a no-label condition. Previous experiments on nutrient warning labels have used a neutral barcode as a control in order to measure perceptions of and reactions to front-of-package labels [20]. However, in this study, we wanted to test actual policies that could be implemented by the Colombian government. It is possible that the government could decide to not implement a front-of- 
package labelling system (status quo), so we also tested a no-label condition to measure the outcomes of maintaining the status quo compared to implementing the nutrient warning label. We used the Peruvian warning labeling guidelines to design the size and placement of the label conditions [25].

\section{Product development and applied labels}

Images of the products can be found in Figure A1. We selected food and drink products from categories that are commonly consumed in Colombia and may not be commonly identified as products high in nutrients of concern. We modeled the products after real Colombian ultra-processed products that are high in nutrients of concern (sugar, sodium, and saturated fat). We used three products we had previously tested (fruit drink, oatmeal cookies, and sliced bread) [20], and the same graphic designer who developed our previous products helped in the development of three new products: a no-sugar-added fruit drink, breakfast cereal, and strawberry yogurt. The breakfast cereal was slightly different from the other products because it contained excess amounts of both sugar and sodium. Therefore, the breakfast cereal fashioned two nutrient warning labels, while the other products only had one. All products contained fictional brand names to avoid consumer brand loyalty bias.

For each labelling system, the presence or absence of the label (nutrient warnings) or content of the labels (Nutri-score, GDA) depended on the nutritional composition of the product. Thus, we created nutrition profiles for each product, based on similar Colombian products. Table 1 provides each product's nutritional profile and the corresponding label applied.

Table 1. Product nutrition details as well as label applied to each product 


\begin{tabular}{|c|c|c|c|c|}
\hline Product & Nutrition profile & $\begin{array}{l}\text { GDA Label (\% of } \\
\text { GDA) }\end{array}$ & $\begin{array}{c}\text { Nutri-Score } \\
\text { Label }\end{array}$ & Nutrient Nutrient warning Label \\
\hline $\begin{array}{l}\text { No-sugar added fruit } \\
\text { drink }\end{array}$ & $\begin{array}{l}\text { Calories: } 33.8 \\
\text { Fat: } 0 \mathrm{~g} \\
\text { Saturated Fat: } 0 \mathrm{~g} \\
\text { Sugars: } 15.8 \mathrm{~g} \\
\text { Sodium: } 33.8 \mathrm{mg} \\
\end{array}$ & $\begin{array}{l}\text { Calories: } 2 \% \\
\text { Fat: } 0 \% \\
\text { Saturated fat: } 0 \% \\
\text { Sugars: } 18 \% \\
\text { Sodium: } 1 \% \\
\end{array}$ & $\mathrm{~B}$ & None \\
\hline Fruit drink & $\begin{array}{l}\text { Calories: } 168.8 \\
\text { Fat: } 0 \mathrm{~g} \\
\text { Saturated Fat: } 0 \mathrm{~g} \\
\text { Sugars: } 39.4 \mathrm{~g} \\
\text { Sodium: } 28.1 \mathrm{mg} \\
\end{array}$ & $\begin{array}{l}\text { Calories: } 8 \% \\
\text { Fat: } 0 \% \\
\text { Saturated Fat: } 0 \% \\
\text { Sugars: } 44 \% \\
\text { Sodium: } 0 \% \\
\end{array}$ & B & Excess sugar \\
\hline Strawberry yogurt & $\begin{array}{l}\text { Calories: } 170 \\
\text { Fat: } 5 \mathrm{~g} \\
\text { Saturated Fat: } 3 \mathrm{~g} \\
\text { Sugars: } 24 \mathrm{~g} \\
\text { Sodium: } 75 \mathrm{mg}\end{array}$ & $\begin{array}{l}\text { Calories: } 9 \% \\
\text { Fat: } 7 \% \\
\text { Saturated Fat: } 15 \% \\
\text { Sugars: } 27 \% \\
\text { Sodium: } 1 \%\end{array}$ & B & Excess sugar \\
\hline Oatmeal cookies & $\begin{array}{l}\text { Calories: } 700 \\
\text { Fat: } 35 \mathrm{~g} \\
\text { Saturated Fat: } \\
15 \mathrm{~g} \\
\text { Sugars: } 15 \mathrm{~g} \\
\text { Sodium: } 200 \mathrm{mg}\end{array}$ & $\begin{array}{l}\text { Calories: } 35 \% \\
\text { Fat: } 50 \% \\
\text { Saturated Fat: } 75 \% \\
\text { Sugars: } 17 \% \\
\text { Sodium: } 3 \%\end{array}$ & $\mathrm{C}$ & Excess saturated fat \\
\hline Sliced bread & $\begin{array}{l}\text { Calories: } 100 \\
\text { Fat: } 2 \mathrm{~g} \\
\text { Saturated Fat: } 1 \mathrm{~g} \\
\text { Sugars: } 0 \mathrm{~g} \\
\text { Sodium: } 180 \mathrm{mg} \\
\end{array}$ & $\begin{array}{l}\text { Calories: } 5 \% \\
\text { Fat: 3\% } \\
\text { Saturated Fat: 5\% } \\
\text { Sugars: 0\% } \\
\text { Sodium: 3\% } \\
\end{array}$ & B & Excess salt/sodium \\
\hline Cereal & $\begin{array}{l}\text { Calories: } 130 \\
\text { Fat: } 2.5 \mathrm{~g} \\
\text { Saturated Fat: } 0 \mathrm{~g} \\
\text { Sugars: } 6 \mathrm{~g} \\
\text { Sodium: } 135 \mathrm{mg}\end{array}$ & $\begin{array}{l}\text { Calories: } 7 \% \\
\text { Fat: } 4 \% \\
\text { Saturated Fat: } 0 \% \\
\text { Sugars: } 7 \% \\
\text { Sodium: } 2 \%\end{array}$ & $\mathrm{C}$ & $\begin{array}{c}\text { Excess sugar; Excess } \\
\text { salt/sodium }\end{array}$ \\
\hline
\end{tabular}

\section{Participants}

In October 2020, we recruited an online national convenience sample of 8,061 adults in Colombia to participate in an experiment. We recruited participants through Offerwise, a market research company with over 300,000 panel participants in Colombia. Inclusion criteria included presently residing in Colombia and being older than 18 years old and younger than 65 years old. We excluded panel members that participated in a previous study of ours investigating the efficacy of different front-of-package nutrient warning labels [20]. We set sample quotas for gender to reflect the Colombian population and for education level (half high school graduate or less, half college degree or higher) to ensure our sample was powered to detect differences in the primary outcome by education level. Participants earned a predetermined amount of points from Offerwise for completing the study. Participants are able to convert points into money once they accumulate a specified amount.

\section{Procedures}


Participants completed an online survey programmed in Spanish using Qualtrics survey software. After providing informed consent, participants were randomized to one of the four front-of-package label conditions: nutrient warning label, Nutri-Score label, GDA label, or a no-label condition. They first completed a selection task, where they were asked a series of questions about two fruit drinks, one of which was healthier (no added sugar) and one of which was less healthy (contained 39.4 grams of sugar). The fruit drinks were displayed according to their randomly assigned condition.

Next, participants completed single product assessment tasks. They viewed a prompt that read: "The next questions are about food products. You will look at a few different products and answer questions about each one. Please keep in mind that this study seeks to evaluate your survey responses and not the sale of the product."Then, they answered a series of questions about the yogurt, cookies, and sliced bread, which showed their assigned label on them. The participants answered all questions about one product at a time (displayed in random order). After these three products, the participants answered one more set of questions about the breakfast cereal. The breakfast cereal was always displayed last as the nutrient warning label condition contained two labels.

Finally, the participants were randomly assigned to see the yogurt, cookies, or sliced bread again (one product only). However, this time, the product did not include a label. Instead, the three label types were listed underneath the product and the participant was asked questions about the labels. The study ended with standard demographic questions.

\section{Measures}

Our study had two primary outcomes, 1 ) selection of the less healthy fruit drink as the fruit drink the participant would rather buy and 2) correctly identifying which fruit drink was higher in sugar. Secondary outcomes included objective understanding, or the ability to correctly identify the less healthy fruit drink, ability to correctly identify if the products contained excess of nutrients of concern, perceived message effectiveness (PME), intentions to purchase the products, and the most discouraging label. All measures were cognitively tested with Colombians of different education levels to make sure the measures were properly adapted to the Colombian context and accessible to all education levels [26].

For the selection task, participants were asked to select one of the two fruit drinks for the following questions: "Which of these products is MOST unhealthy?", "Which of these products is higher in sugar?", and "Which of these products would you rather buy?" Both the order of the three questions and the position of each fruit drink (left or right) were randomized.

Next, for the questions about the yogurt, cookies, and sliced bread, we measured objective understanding, or whether participants could correctly identify if the product contained excess of the nutrient of concern (sugar, sodium, or saturated fat respectively) (yes/no?), and we measured the participants' likelihood of wanting to purchase the product in the next week if it were available (range from "very much" (coded as 5) to "not at all" (coded as 1)). 
We also measured PME of the labels, using three items from the UNC perceived message effectiveness scale [27, 28]which read: "How much does the label..." "make you worried about the health consequences of consuming this product?" (range from "very much" (coded as 5) to "not at all" (coded as 1)), "make consuming this product seem unpleasant to you?" (range from "very much" (coded as 5) to "not at all" (coded as 1)), and "discourage you from wanting to consume this product?" (range from "very much" (coded as 5) to "not at all" (coded as 1)). Because PME is specifically about labels, we did not measure PME for the no-label condition. For the breakfast cereal, we measured participants' ability to correctly identify if the product contained excess of the nutrients of concern (sugar and sodium), and we measured PME.

Finally, when participants viewed all three label types below one of the randomly selected products (yogurt, cookies, bread), they were asked to select which label would most discourage them from wanting to consume the product.

\section{Analyses}

All analyses were conducted in STATA version 16.0. A two-sided critical alpha of 0.05 was used to assess statistical significance. Using G.Power 3.1.9.4, we estimated that with a sample of $\sim 8,000$, alpha of 0.05 , and $80 \%$ power, we could detect an effect of $f=0.036$. We excluded participants from analysis if they were duplicate responders (dropped all responses except first), completed the study in less than two minutes, or if they did not answer at least one primary or secondary outcome (see Figure 2).

We calculated unadjusted means (and standard deviations) and percentages for the primary and secondary outcomes. For our secondary outcome, PME, we took the average of the 3 items for each product type (Cronbach's alpha for each product type>.70). We then assessed whether primary and secondary outcomes varied by condition compared to the nutrient warning label. Because the breakfast cereal contained excess of two nutrients of concern, we examined whether the breakfast cereal outcomes exhibited the same pattern prior to adding them to the overall reported measures. We used linear regression for continuous outcomes (including PME) and logistic regression for binary outcomes. For outcomes that were assessed using repeated measures for multiple product types, we used mixed models treating the intercept as random at the respondent level to account for repeated measures. These models included the between-subjects factor (i.e., label type), the within-subjects factor (i.e., product type), and their interaction. We conducted pairwise comparisons of the predicted means or predicted percentages between each label type. We applied Holm's sequentially rejective procedure [29] to the primary outcomes, objective understanding, the ability to identify if the products contained excess of nutrients of concern, and the likelihood of purchasing the product if it were available to account for multiple comparisons.

To evaluate the most discouraging label, we examined the proportion of participants that selected each label type as the one that most discouraged them from consuming products high in sugar, sodium, or saturated fat. 
Finally, to assess whether the effect of label type on the primary outcomes differed by education, we tested for an interaction of nutrient warning with education level specified as low (high school diploma or less) vs. high (college degree or higher) and used a Wald chunk test to determine the joint interaction. We conducted pairwise comparisons to predict percentages by label type and education level.

\section{Results}

Descriptive statistics

Participant characteristics are listed in Table 2. Raw means and proportions can be found in Tables A1 and $\mathrm{A} 2$.

Table 2. Socio-demographic characteristics $(n=8,061)$ 


\begin{tabular}{|c|c|c|}
\hline & $\mathrm{n}$ & $\%$ \\
\hline \multicolumn{3}{|l|}{ Label condition } \\
\hline No label & 2113 & $26.2 \%$ \\
\hline Nutri-Score & 1974 & $24.5 \%$ \\
\hline Nutrient warning & 1999 & $24.8 \%$ \\
\hline GDA & 1975 & $24.5 \%$ \\
\hline \multicolumn{3}{|l|}{ Age } \\
\hline $18-24$ & 3028 & $37.6 \%$ \\
\hline $25-34$ & 2488 & $30.9 \%$ \\
\hline $35-44$ & 1603 & $19.9 \%$ \\
\hline $45-54$ & 723 & $9.0 \%$ \\
\hline $55-64$ & 219 & $2.7 \%$ \\
\hline \multicolumn{3}{|l|}{ Gender } \\
\hline Man & 3910 & $48.5 \%$ \\
\hline Woman & 4118 & $51.1 \%$ \\
\hline Other gender identity & 33 & $0.4 \%$ \\
\hline \multicolumn{3}{|l|}{ Body mass index (BMI, $\left.\mathrm{kg} / \mathrm{m}^{\wedge} 2\right)$} \\
\hline Underweight $(<18.5)$ & 546 & $7.1 \%$ \\
\hline Healthy weight (18.5-24.9) & 4148 & $53.6 \%$ \\
\hline Overweight (25.0 - 29.9) & 2153 & $27.8 \%$ \\
\hline Obese $(>29.9)$ & 891 & $11.5 \%$ \\
\hline Mean BMI (SD) & 24.8 & 6.7 \\
\hline \multicolumn{3}{|l|}{ Education level } \\
\hline $\begin{array}{l}\text { Low } \\
\text { (High school diploma or less) }\end{array}$ & 4010 & $49.7 \%$ \\
\hline $\begin{array}{l}\text { High } \\
\text { (College degree or higher) }\end{array}$ & 4051 & $50.3 \%$ \\
\hline \multicolumn{3}{|l|}{ Region } \\
\hline Atlantica & 1094 & $13.7 \%$ \\
\hline Oriental & 1189 & $14.9 \%$ \\
\hline Central & 1655 & $20.7 \%$ \\
\hline Pacifica & 1095 & $13.7 \%$ \\
\hline Orinoquia & 87 & $1.1 \%$ \\
\hline Bogota & 2856 & $35.8 \%$ \\
\hline \multicolumn{3}{|l|}{ Children in household (ages 0-18) } \\
\hline Yes & 5,286 & $66 \%$ \\
\hline \multicolumn{3}{|l|}{ Ethnicity } \\
\hline Indigenous & 138 & $1.7 \%$ \\
\hline Afro-descendent & 445 & $5.6 \%$ \\
\hline White & 2192 & $27.4 \%$ \\
\hline Mestizo & 3258 & $40.8 \%$ \\
\hline Other ethnic group & 497 & $6.2 \%$ \\
\hline No ethnic group & 1462 & $18.3 \%$ \\
\hline \multicolumn{3}{|l|}{ Financial situation } \\
\hline Can pay bills and buy additional things & 2213 & $27.8 \%$ \\
\hline Can pay bills and buy what is needed & 3470 & $43.5 \%$ \\
\hline Can pay bills but not buy everything that is needed & 1674 & $21 \%$ \\
\hline Can't pay the bills & 616 & $7.7 \%$ \\
\hline
\end{tabular}

Note. Missing demographic data ranged from $0 \%$ to $4.01 \%$. 


\section{Choice experiment}

In the fruit drink selection task, the nutrient warning label was more effective than the no-label, GDA, and Nutri-Score conditions at decreasing the percentage of people who wanted to purchase the less-healthy fruit drink. Twenty percent of participants in the nutrient warning condition selected the less healthy fruit drink as the drink they most wanted to buy compared to $24 \%$ in the GDA condition, $29 \%$ in the no-label condition, and 33\% in the Nutri-Score condition ( $p<.001$ for Nutri-Score and no-label conditions compared to the nutrient warning, adjusted; $p<0.01$ for GDA condition compared to the nutrient warning, adjusted) (see Figure 3).

The nutrient warning label was also more effective at helping consumers identify which fruit drink was higher in sugar, relative to the no-label and Nutri-score conditions; while only $65 \%$ in the Nutri-Score condition and $68 \%$ in the no-label condition correctly identified the fruit drink higher in sugar, $88 \%$ in the nutrient warning condition were able to correctly identify which fruit drink was higher in sugar $(p<0.001$ for both conditions compared to the nutrient warning, adjusted). The GDA label was more effective than the nutrient warning label with $91 \%$ of participants in the GDA condition correctly identifying which fruit drink was higher in sugar ( $p<0.01$ compared to the nutrient warning, adjusted).

Finally, when asked which fruit drink was less healthy, the nutrient warning label increased the likelihood of correctly identifying the less healthy fruit drink with $87 \%$ in the nutrient warning condition making the correct identification compared to $68 \%$ in the Nutri-Score condition and $71 \%$ in the no-label condition $(p<.001$ for both conditions compared to the nutrient warning, adjusted). There were no differences between the nutrient warning and GDA labels.

\section{Interaction of label type and education}

There were no significant interactions between education level and condition $(p=0.521)$. In particular, the difference between education levels in selecting the less healthy fruit drink was similar among each condition compared to the difference between education levels in the nutrient warning condition (see Figure 4). In other words, education level had a similar interaction across all conditions compared to the nutrient warning condition.

However, the difference between high versus low education levels on the likelihood of correctly identifying the fruit drink higher in sugar was greater in the Nutri-Score condition compared to the nutrient warning condition $(p<0.01)$ (Figure 5). In other words, education level had a greater interaction in the Nutri-Score group compared to the nutrient warning condition.

Single product assessment of yogurt, bread, cookies, and cereal high in sugar, sodium, saturated fat, or sugar and sodium

In the single product assessment tasks, compared to the no-label, Nutri-Score, and GDA conditions, the nutrient warning was more effective in helping participants to correctly identify that the product contained excess of the nutrient of concern and more effective in decreasing the participants' likelihood 
of wanting to purchase the product if it were available (Table 3; $p<.001$ for each condition compared to the nutrient warning label). While $75 \%$ of participants in the nutrient warning condition correctly identified that the product contained excess of the nutrient of concern, only $23 \%$ in the no-label condition, $26 \%$ in the Nutri-Score condition, and $43 \%$ in the GDA condition were able to do so. The nutrient warning also led to greater perceived message effectiveness compared to both the Nutri-Score and GDA ( $p<.001$ for each condition compared to the nutrient warning label; PME not applicable in the no-label condition).

Table 3. Predicted percent and predicted means of secondary outcomes, by label type

\begin{tabular}{|c|c|c|c|c|c|c|c|c|c|}
\hline & \multicolumn{3}{|c|}{$\begin{array}{l}\text { Correctly identified product as having } \\
\text { excess of nutrient }\end{array}$} & \multicolumn{3}{|c|}{$\begin{array}{l}\text { Likelihood of purchasing the product in the next } \\
\text { week if it were available }\end{array}$} & \multicolumn{3}{|c|}{ PME } \\
\hline & $\%$ & $\mathrm{SE}(\mathrm{pp})$ & $p$ & Mean & $\mathrm{SE}$ & $p$ & Mean & $S E$ & $p$ \\
\hline \multicolumn{10}{|l|}{ Condition } \\
\hline $\begin{array}{l}\text { Nutrient } \\
\text { warning }\end{array}$ & $75 \%$ & 0.01 & (ref) & 2.58 & 0.02 & (ref) & 3.86 & 0.02 & (ref) \\
\hline No label & $23 \%$ & 0.01 & $<.001$ & 3.51 & 0.02 & $<.001$ & - & - & - \\
\hline \multicolumn{10}{|l|}{$\begin{array}{l}\text { Nutri- } \\
\text { Score }\end{array}$} \\
\hline GDA & $43 \%$ & 0.01 & $<.001$ & 3.23 & 0.02 & $<.001$ & 2.97 & 0.02 & $<.001$ \\
\hline
\end{tabular}

\section{Other outcomes}

Participants overwhelmingly selected the nutrient warning label as the one that most discouraged them from wanting to consume a product high in sugar, saturated fat, or sodium (Figure 6). Seventy-two percent of participants selected the nutrient warning label as most discouraging compared to only $20 \%$ selecting the GDA label and $9 \%$ selecting the Nutri-Score label.

\section{Discussion}

This online randomized control trial aimed to assess the impact of nutrient warning labels on product selection and identification of less healthy products, among other outcomes, compared to GDA labels, Nutri-Score labels, and no label, among adults aged 18 to 64 years in Colombia. In general, the pattern of results suggests that nutrient warning labels are most effective at achieving desired outcomes. The nutrient warning labels were more effective than other label types at discouraging Colombian consumers from wanting to purchase the less healthy fruit drink. Furthermore, they were more effective in decreasing the likelihood of wanting to purchase products high in sugar, sodium, and saturated fat; increasing the ability to correctly identify the products that contained excess of these nutrients of concern; as well as, increasing PME. When comparing the GDA, Nutri-Score, and nutrient warning labels, consumers were most likely to select the nutrient warning label as the one that most discouraged them from wanting to consume products high in sugar, saturated fat, or sodium. The difference between high and low 
education levels on product selection was similar among all conditions, compared to the nutrient warning, suggesting that a nutrient warning label policy would not differentially affect adults with low versus high educational levels more than any other label or no-label policy. These results illustrate the benefits of nutrient warning labels and support the need for policies in Colombia that require this labeling system on products high in nutrients of concern.

The findings of this study regarding nutrient warnings are consistent with prior studies conducted in several Latin American countries [30]. Although the pattern of results suggests that nutrient warnings consistently performed best relative to the GDA, Nutri-Score, and no-label conditions, it is important to note that the GDA label had a slightly better performance (91\%) than the octagonal nutrient warning label $(88 \%)$ at helping consumers identify which fruit drink was higher in sugar when comparing two fruit drinks. One possible reason for this could be due to the large difference in sugar content of the two fruit drinks. While the healthier fruit drink contained $18 \%$ of the daily value of sugar, the less healthy fruit drink contained $44 \%$ of the daily value of sugar; a difference of 26 percentage points. In a real life shopping situation, the ability to closely compare GDA labels on different products might be more limited as people have less time to examine the labels in detail [31]. In addition, the nutrient warning label performed better than the GDA on the majority of other outcomes, including: helping consumers to correctly identify products as having excess of sugar, saturated fat, or sodium; discouraging purchasing the product in the next week if it were available; and increasing perceived message effectiveness.

This study found that the nutrient warning labels performed better than Nutri-Score on several outcomes. These findings are similar to those of a study conducted in Uruguay, which reported that nutrient warnings were more effective than Nutri-Score in decreasing intentions to purchase unhealthy products [32]. This may be due to the fact that nutrient warning labels provide information in a binary fashion (either the product is high-in or not high-in) which can capture attention and facilitate better understanding compared to other labelling schemes. For example, in this research study, in the nutrient warning condition the fruit drink with added sugar contained an excess sugar warning and the fruit drink without added sugar did not contain a warning, making it easier to identify the less healthy product. Alternatively, in the Nutri-Score condition, based on the Nutri-Score point system, both fruit drinks had the same Nutri-Score of " $\mathrm{B}$ " making it more difficult to identify the less healthy product. Future research is needed to understand mediating factors on the pathway between label exposure and behavioral outcomes.

Regarding educational level moderation analyses, there were almost no significant differences in the difference between educational levels in each condition compared to the differences in the nutrient warning condition. This study provides evidence that the nutrient warning label would not exacerbate the difference between people of high versus low educational levels in their likelihood of selecting a less healthy fruit drink or in their ability to correctly identify a fruit drink higher in sugar. This is important considering the beneficial impact that promoting information on healthy food choices could have among the most vulnerable populations, such as those with lower levels of literacy and/or financial resources [33]. Alternatively, in this study the Nutri-Score label did have a greater difference between high versus low 
education levels, compared to the nutrient warning, in the ability of the groups to correctly identify the fruit drink higher in sugar. This result was contrary to many other study findings [34,35], Therefore, more studies must be conducted to understand the role of education and how this label is understood by Colombians and other Latin-American populations.

\section{Strengths and limitations}

This is the first randomized online experiment to be carried out in Colombia that assessed the effectiveness of several labelling nutrition systems. In addition, this study used standardized questions from previous studies, which have shown appropriate psychometric characteristics $[20,27,28]$.

However, limitations to the research exist. Firstly, because this study examined real-world nutrition labels, we were unable to assess what specific characteristics of each label influenced participants' responses. Nevertheless, the use of real-world labels enabled us to study the effectiveness of labelling systems that could actually be implemented in Colombia. Secondly, although the study population included participants from different Colombian regions, most of them lived in urban areas, which could restrict the external validity of the study. However, the study population included adults from different Colombian regions with diverse social identities which may attenuate this external validity limitation. Finally, this study does not examine the impact of labels on real-world consumer behaviors. However, results from a recent meta-analysis [28] have found that nutrient warning labels are effective at reducing objectively measured purchases of sugar-sweetened beverages; and, the first study to evaluate a real-world nutrient warning label system found that after its implementation, purchases of sugar-sweetened beverages dropped by $24 \%[20]$.

\section{Conclusion}

Front-of-package nutrient warning labels are a promising policy strategy to help combat overweight, obesity, and diet-related NCD in Colombia. The overall pattern of results showed that nutrient warning labels decreased consumers' selection of an less healthy product and improved consumers' ability to identify a less healthy product, as well as when a product is high in nutrients of concern, when compared to no label, Nutri-Score label, and GDA. The one exception was that GDA performed better than the nutrient warning at helping participants to identify a high-sugar fruit drink, though the magnitude of the effect was small. Overall, the nutrient warning label most consistently performed best in achieving intended outcomes. Future research is needed to understand the impact of nutrient labels on actual ultraprocessed food purchases in Colombia.

\section{List Of Abbreviations}

ENSIN - Colombian National Nutritional Health Survey

GDA - Guideline daily amounts 
NCD - Non-communicable diseases

PME - Perceived message effectiveness

\section{Declarations}

\section{Ethics approval and consent to participate}

The study was approved by the institutional review board at the University of North Carolina at Chapel Hill (IRB \#20-0401) and designated as exempt from review at Universidad Nacional de Colombia.

\section{Consent for publication}

Not applicable

\section{Availability of data and materials}

The datasets used and analysed during the current study are available from the corresponding author on reasonable request.

\section{Competing interests}

The authors declare that they have no competing interests

\section{Funding}

Funding support was provided by Bloomberg Philanthropies. Additional support for LST, MGH, MB and IH was provided by NICHD of the National Institutes of Health under award number P2C HD050924 and by NIA of the National Institutes of Health under award number P30 AG066615. MGH was also supported by K01HL147713 from the National Heart, Lung, and Blood Institute of the NIH. The content is solely the responsibility of the authors and does not necessarily represent the official views of any funder. The funders had no role in the design of the study; in the collection, analyses, or interpretation of data; in the writing of the manuscript, or in the decision to publish the results.

\section{Authors' contributions}

Conceptualization, LST, LFG, MM; methodology, LST, MH, ICAH, NM, LFG, MM, MFP; formal analysis, ICAH, LST, MB; writing-original draft preparation, MM, ICAH, LFG; writing-review and editing, LST, MB, MH, NM, ICAH, LFG, MM, MFP; project administration, LST; funding acquisition, LFG, MM, LST. All authors have read and agreed to the published version of the manuscript.

\section{Acknowledgements}

The authors would like to thank the UNC Global Food Research Program and Javeriana team. In particular, we thank Dr. Barry Popkin for his insight on the global food policy landscape, Dr. Yazmin 
Cadena for advising and providing insight into the cognitive interview process, Emily Busey for her assistance developing the images used in this study, Carmen Prestemon for programming the survey, and Cindy P. Evans for assisting in the development of nutritional profiles for all products.

\section{References}

[1] Patterson D, Buse K, Magnusson R, et al. Identifying a human rights-based approach to obesity for States and civil society. Obes Rev. 2019; 20:45-56.

[2] The GBD 2015 Obesity Collaborators. Health effects of overweight and obesity in 195 countries over 25 years. $N$ Engl J Med. 2017;377:13-27.

[3] Fardet A, Rock E. Ultra-processed foods and food system sustainability: what are the links? Sustainability. 2020;12:6280.

[4] Monteiro CA, Cannon G, Moubarac J-C, et al. The UN Decade of Nutrition, the NOVA food classification and the trouble with ultra-processing. Public Health Nutr. 2018;21:5-17.

[5] Monteiro CA, Cannon G, Levy RB, et al. Ultra-processed foods: what they are and how to identify them. Public Health Nutr. 2019;22:936-941.

[6] Popkin B. Ultra-processed foods' impacts on health. 2030 - Food, agriculture and rural development in Latin America and the Caribbean, No. 34. FAO. 2019. http://www.wipo.int/amc/en/mediation/rules. Accessed 20 January 2021.

[7] PAHO. Pan American Health Organization Nutrient Profile Model. Cat 2. Noncommunicable Diseases and Risk Factors. 2016; 1-34.

[8] Popkin BM, Corvalan C, Grummer-Strawn LM. Dynamics of the double burden of malnutrition and the changing nutrition reality. The Lancet. 2020;395:65-74.

[9] Juul F, Martinez-Steele E, Parekh N, et al. Ultra-processed food consumption and excess weight among US adults. Br J Nutr. 2018;120:90-100.

[10] Pagliai G, Dinu M, Madarena MP, et al. Consumption of ultra-processed foods and health status: a systematic review and meta-analysis. Br. J. Nutr. 2020;125:308-318.

[11] Rauber F, Louzada ML da C, Steele EM, et al. Ultra-processed food consumption and chronic noncommunicable diseases-related dietary nutrient profile in the UK (2008-2014). Nutrients. 2018;10:587.

[12] Instituto Colombiano de Bienestar Familiar (ICBF). Encuesta Nacional de la Situación Nutricional en Colombia 2015. Bogotá, Colombia, 2015. 
[13] Instituto Colombiano de Bienestar Familiar (ICBF). Encuesta Nacional de la Situación Nutricional en Colombia 2005. Bogotá, Colombia, 2005.

[14] Scrinis G, Monteiro CA. Ultra-processed foods and the limits of product reformulation. Public Health Nutr. 2018;21:247-252.

[15] Khandpur N, Cediel G, Obando DA, et al. Sociodemographic factors associated with the consumption of ultra-processed foods in Colombia. Rev Saude Publica. 2020; 54:19.

[16] Kanter R, Vanderlee L, Vandevijvere S. Front-of-package nutrition labelling policy: global progress and future directions. Public Health Nutr. 2018;21:1399-1408.

[17] Reyes M, Garmendia ML, Olivares S, et al. Development of the Chilean front-of-package food warning label. BMC Public Health. 2019; 19:906.

[18] Ministerio de Salud y Protección Social de Colombia. Análisis de impacto normativo en la temática de etiquetado nutricional y frontal de los alimentos envasados en Colombia. 2016. https://www.minsalud.gov.co/Normativa/Documents/AIN etiquetado V02032020.pdf.

[19] República De Colombia. Senado Y Cámara (Artículo 36, Ley 5a De 1992). Artículo 36, Ley 5a De 1992, Imprenta Nacional De Colombia, www.secretariasenado.gov.co (2020, accessed 20 January 2021).

[20] Taillie LS, Hall MG, Gómez LF, et al. Designing an effective front-of-package warning label for food and drinks high in added sugar, sodium, or saturated fat in Colombia: An online experiment. Nutrients. 2020;12:1-20.

[21] Ministerio de Salud - Gobierno de Chile. Ley de alimentos: manual de etiquetado nutricional. 2019. https://www.minsal.cl/ley-de-alimentos-manual-etiquetado-nutricional/. Accessed 20 January 2021.

[22] The Food and Drink Federation. Delivering Sustainable Growth. GDA Labelling. https://www.gdalabel.org.uk/gda/gdalabel.html. Accessed 20 January 2021.

[23] Deschasaux M, Huybrechts I, Julia C, et al. Association between nutritional profiles of foods underlying Nutri-Score front-of-pack labels and mortality: EPIC cohort study in 10 European countries. BMJ. 2020;370:m3173.

[24] COLRUYTGROUP. Nutri-Score, a simple labelling system for nutritional value. https://nutriscore.colruytgroup.com/colruytgroup/en/about-nutri-score/. Accessed 20 January 2021.

[25] Peru Supreme Decree 012-2018-SA. Manual on Advertising Warnings approved pursuant to the provisions of Law No. 30021, Law to Promote Healthy Eating for Children and Adolescents, and its Regulations approved by Supreme Decree No. 017-2017-SA. Lima, Peru, 2018. 
[26] Willis GB. Cognitive Interviewing: a tool for improving questionnaire design. SAGE Publications, Inc; 2005.

[27] Baig SA, Noar SM, Gottfredson NC, et al. UNC Perceived Message Effectiveness: Validation of a Brief Scale. Ann Behav Med. 2018;53:732-742.

[28] Grummon AH, Hall MG, Taillie LS, et al. How should sugar-sweetened beverage health warnings be designed? A randomized experiment. Prev Med. 2019;121:158-166.

[29] Holm S. A simple sequentially rejective multiple test procedure. Scand. J. Stat. 1979;6:65-70.

[30] Taillie LS, Hall MG, Popkin BM, et al. Experimental studies of front-of-package nutrient warning labels on sugar-sweetened beverages and ultra-processed foods: a scoping review. Nutrients. 2020;12:569.

[31] Jáuregui A, Vargas-Meza J, Nieto $C$, et al. Impact of front-of-pack nutrition labels on consumer purchasing intentions: a randomized experiment in low- and middle-income Mexican adults. BMC Public Health. 2020;20:463.

[32] Ares G, Varela F, Machin L, et al. Comparative performance of three interpretative front-of-pack nutrition labelling schemes: insights for policy making. Food Qual Prefer. 2018;68:215-225.

[33] Feteira-Santos R, Fernandes J, Virgolino A, et al. Effectiveness of interpretive front-of-pack nutritional labelling schemes on the promotion of healthier food choices: a systematic review. Int J Evid Based Healthc. 2020;18:24-37.

[34] Egnell M, Talati Z, Galan P, et al. Objective understanding of the Nutri-score front-of-pack label by European consumers and its effect on food choices: an online experimental study. Int J Behav Nutr Phys Act. 2020;17:146.

[35] Mora-García CA, Tobar LF, Young JC. The effect of randomly providing nutri-score information on actual purchases in Colombia. Nutrients. 2019;11:491.

\section{Figures}




\section{EXCESO DE}

AZÚCARES

MINSALUD

\section{EVITAR SU ALTO CONSUMO}

"Nutrient warning"

Una porción de $\mathbf{2 0 0} \mathrm{g}$ aporta:
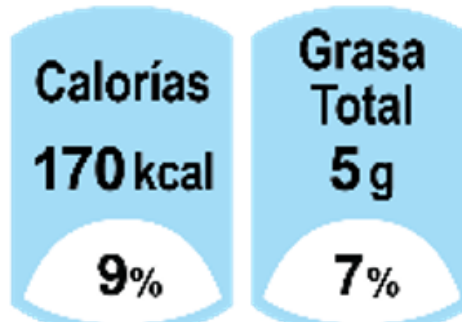

Grasa
Saturada

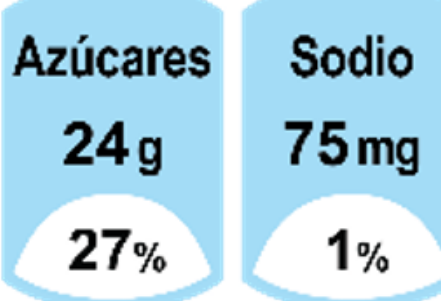

De los valores diarios de referencia de nutrientes en una dieta de $2000 \mathrm{kcal}$. "GDA"

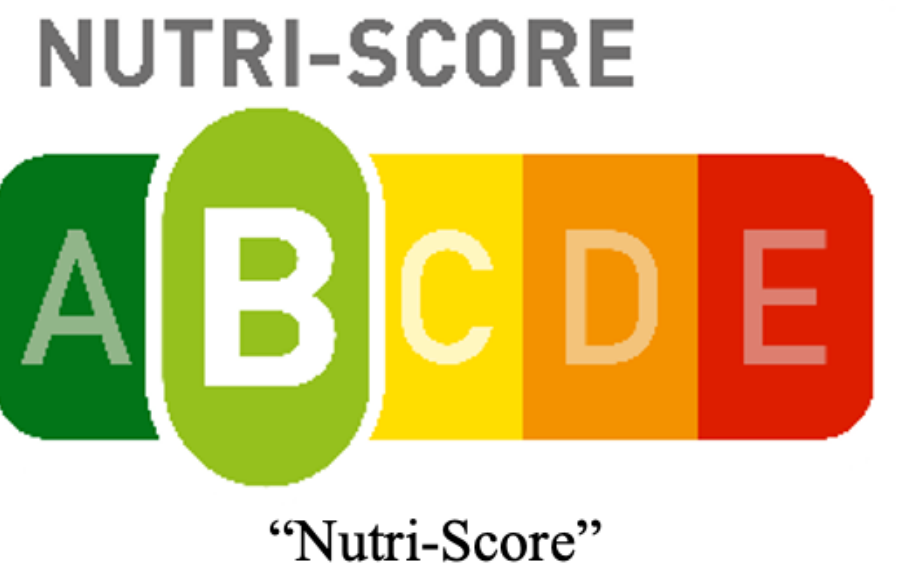

Figure 1

Front-of-package labels used in experiment. Note. Labels listed above represent the version of each label used on the yogurt (excess sugar). 


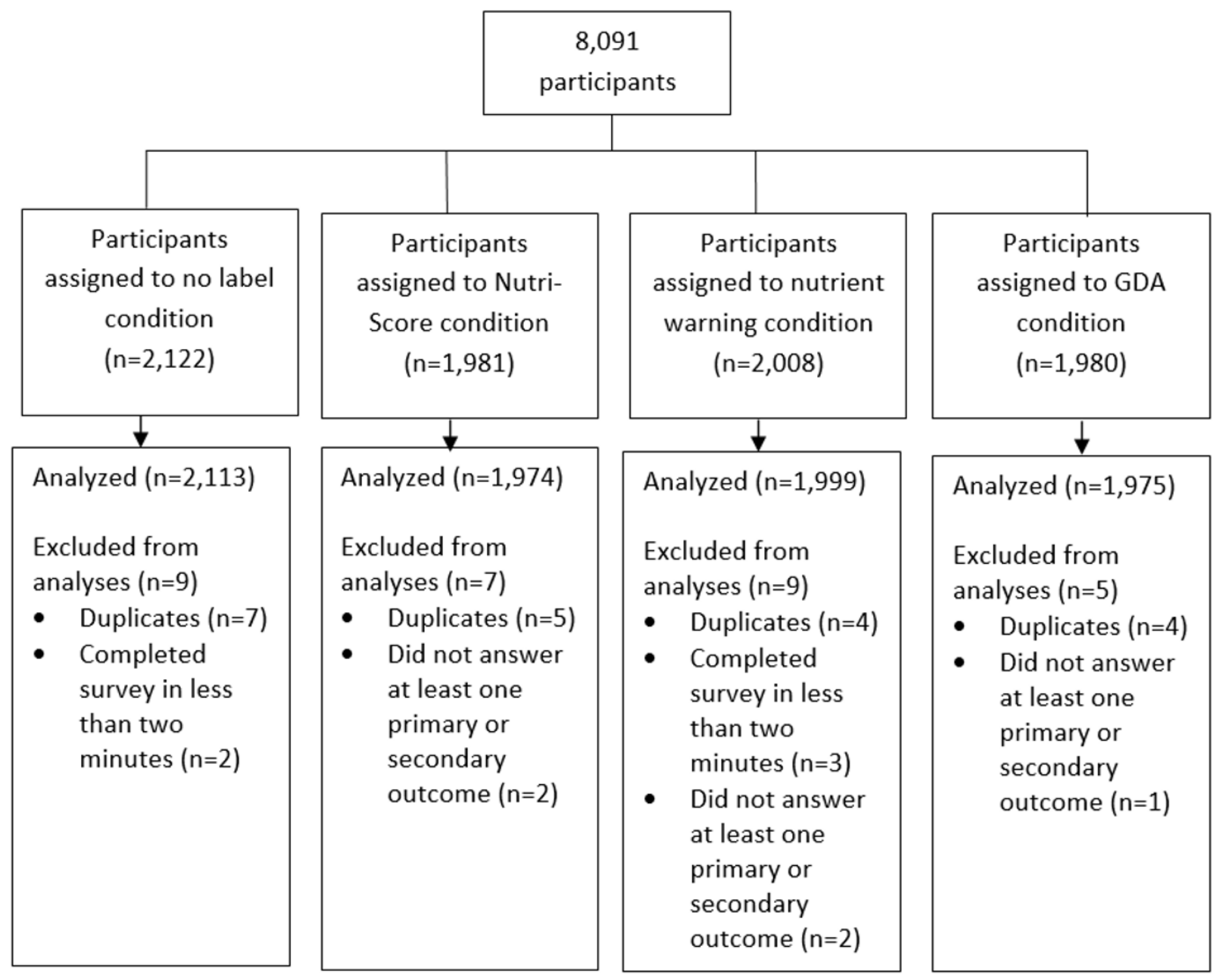

Figure 2

CONSORT Flow Diagram 


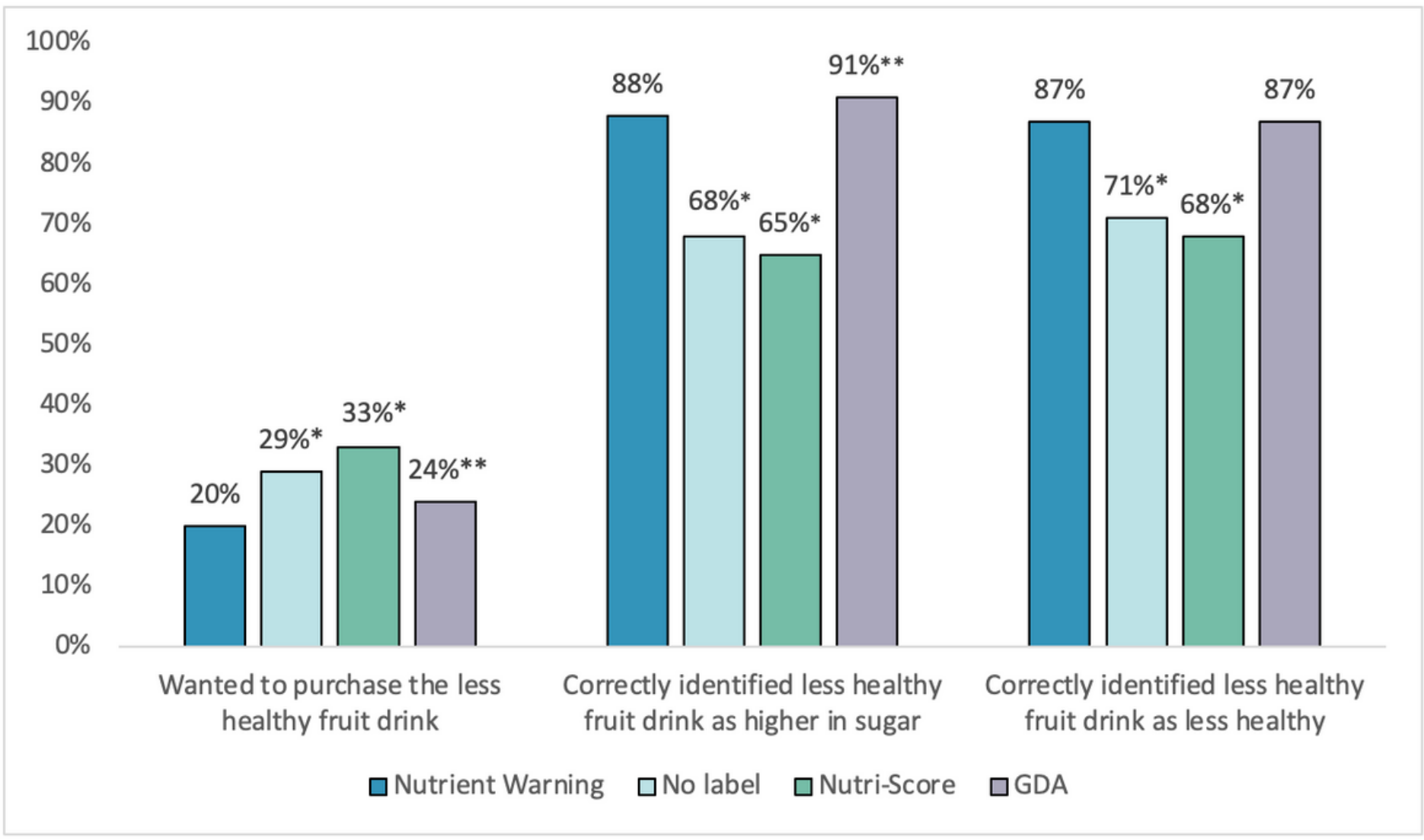

Figure 3

Predicted percent participants, by label condition. Note. ${ }^{*} p<0.001$ compared to nutrient warning. ${ }^{* \star} p<0.01$ compared to nutrient warning. 


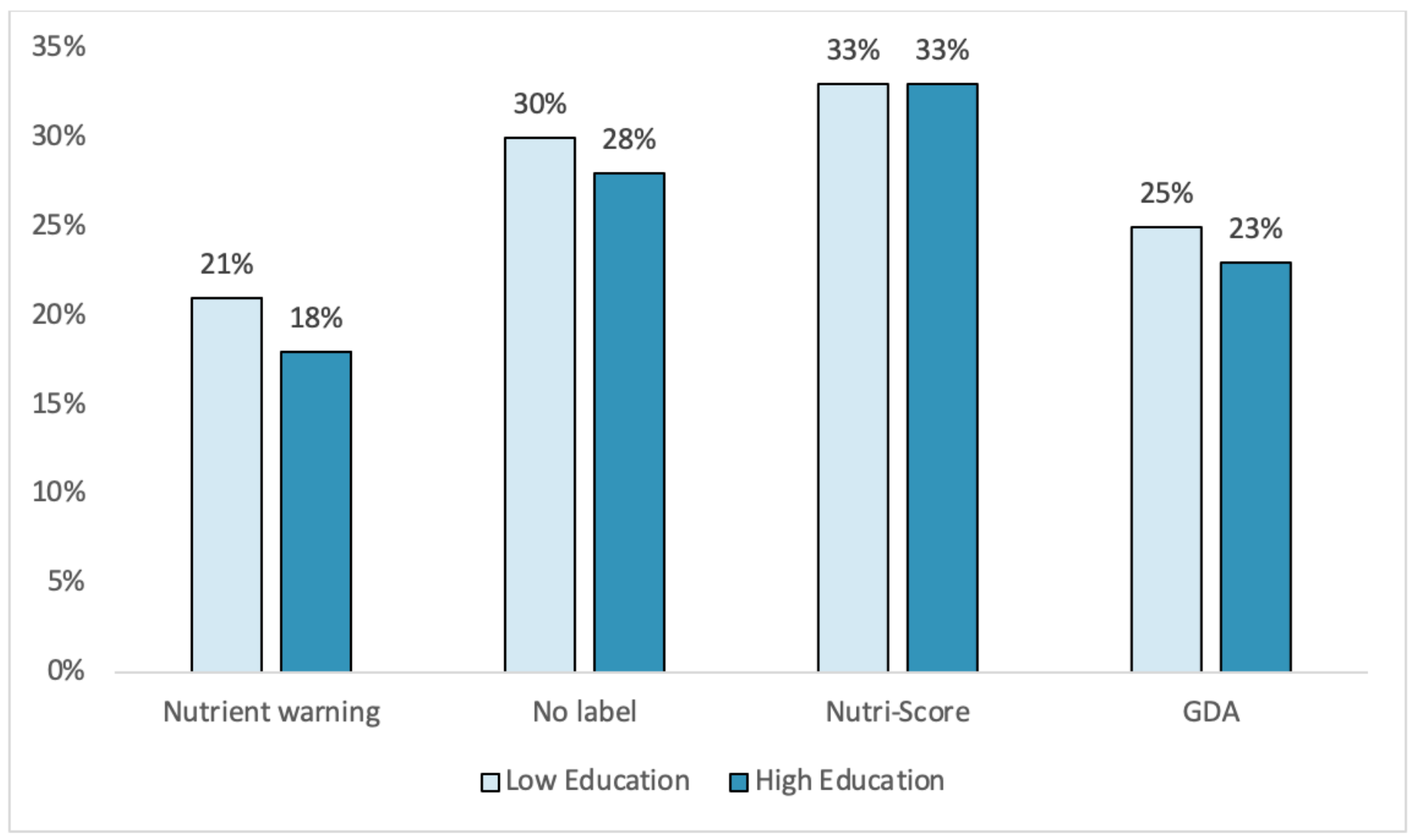

Figure 4

Impact of label condition on wanting to buy less healthy fruit drink, by education level. Note. P-value for joint Wald test for the interaction of front-of-package label types and education levels $=0.52$. Comparing each label condition to the nutrient warning, all had a similar difference between education levels (high versus low) on the likelihood of purchasing the less healthy fruit drink ( $p>05)$. 


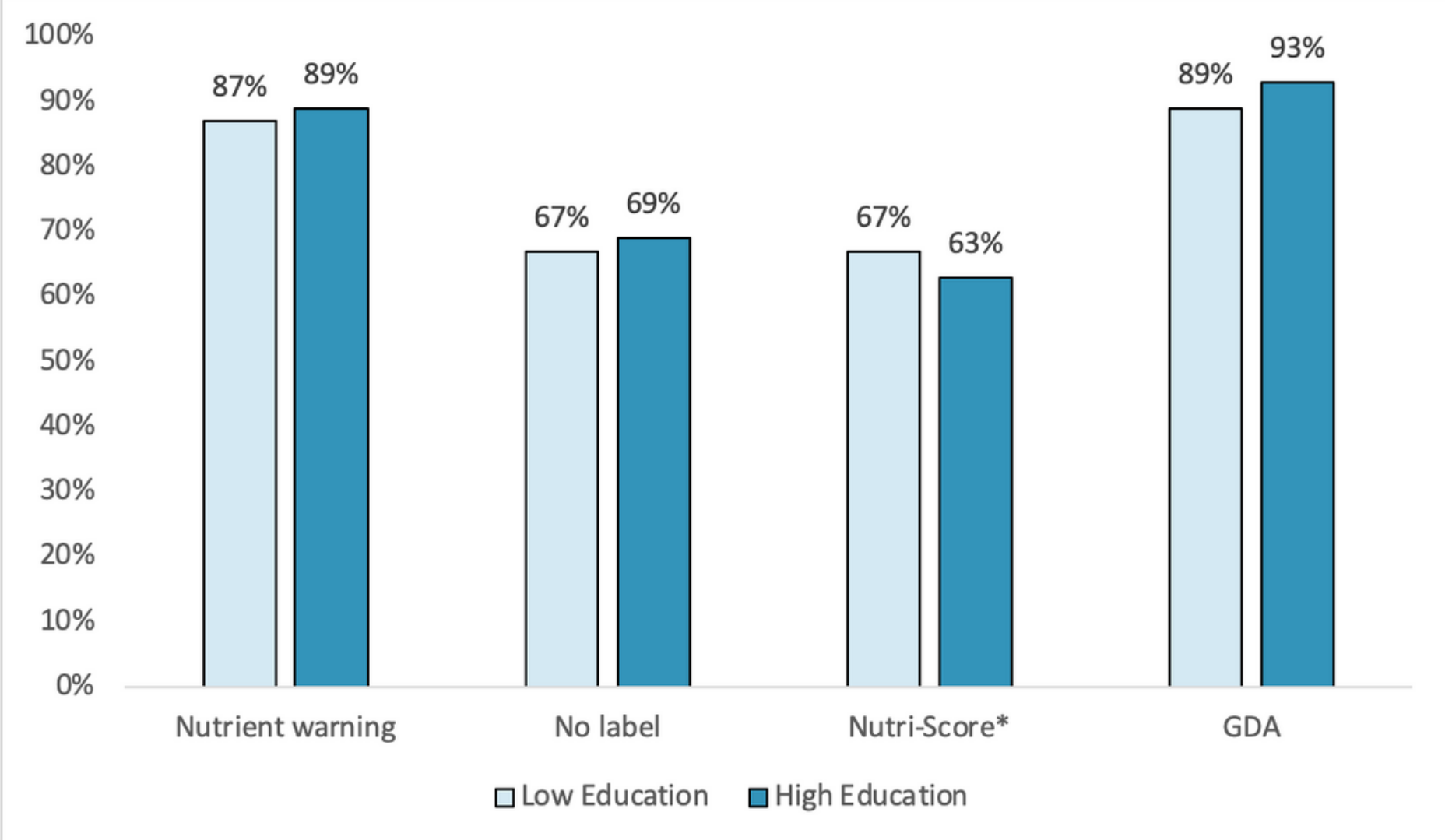

\section{Figure 5}

Impact of label condition on correctly identifying fruit drink higher in sugar, by education level. Note. Pvalue for joint Wald test for the interaction of front-of-package label type and education level <.01. *The difference between high versus low education on the likelihood correctly identifying the fruit drink higher in sugar in the Nutri-Score condition was significantly greater than the difference between high versus low education in the nutrient warning condition $(p<.05)$. 


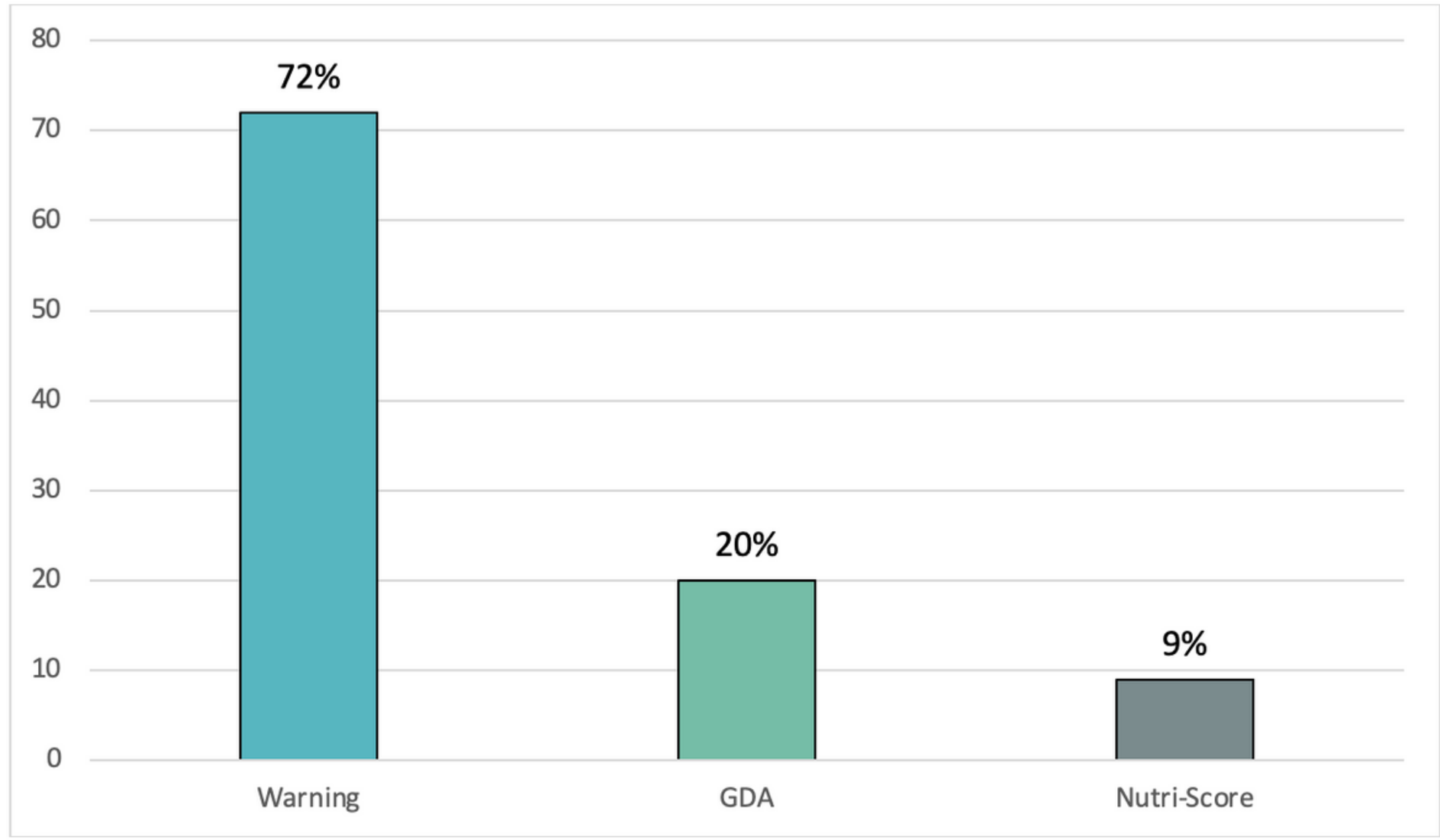

\section{Figure 6}

Percent of participants selecting each label as the most discouraging

\section{Supplementary Files}

This is a list of supplementary files associated with this preprint. Click to download.

- Appendix.docx 